\title{
Cerebellopontine Angle Meningioma
}

National Cancer Institute

\section{Source}

National Cancer Institute. Cerebellopontine Angle Meningioma. NCI Thesaurus. Code C5300.

A mening ioma that affects the cerebellopontine angle. 